\title{
Research and Countermeasure Analysis of College Students' Employment Issues
}

\author{
Jinzhe Chu, Jiali Liu, Shaoqin Liu \\ Heilongjiang Bayi Agricultural University, Daqing, China \\ Email: 1203213079@qq.com
}

How to cite this paper: Chu, J.Z., Liu, J.L. and Liu, S.Q. (2020) Research and Countermeasure Analysis of College Students' Employment Issues. Open Journal of Social Sciences, 8, 129-138.

https://doi.org/10.4236/jss.2020.81011

Received: December 31, 2019

Accepted: January 11, 2020

Published: January 14, 2020

Copyright $\odot 2020$ by author(s) and Scientific Research Publishing Inc. This work is licensed under the Creative Commons Attribution International License (CC BY 4.0).

http://creativecommons.org/licenses/by/4.0/

\begin{abstract}
College students are engineers of national development and construction, and they are the future and hope of China. With the expansion of colleges and universities across the country, the number of college graduates has increased year by year recently, and "employment difficulties" among college students have become increasingly prominent in recent years. The difficulties of employment affect not only the stable development of society, but also the happy lives of the people which have drawn great attention from society. The difficulty of employment has also become a problem that the country must solve now. China has issued a number of policies in response to this problem. Colleges and universities have also focused on cultivating social talents and expanding the employment market for college students in accordance with social and market needs. This article elaborates the employment status of college students at home and abroad, analyzes the problems faced by college students in China, and puts forward countermeasures and suggestions for promoting college students' employment in China, aiming at helping college students solve the employment difficulties.
\end{abstract}

\section{Keywords}

College Students, Employment Difficulties, Countermeasure Analysis

\section{Employment Status of College Students}

The employment of college students has become an issue that draws common concern from the whole society [1]. With the development of science and technology, more and more positions in physical enterprises and industries have disappeared in history, replaced by emerging industries. The Internet industry for instance has become a hot industry today, and the real economy is facing a huge crisis under the impact of the Internet industry. Thus the issue of "employment difficulties" has become a hot issue in society today. College students 
who graduated in the 1990s can be said to be almost $100 \%$ employed. On the one hand, a mechanism of mandatory distributions dominated at that time; on the other hand, college students were relatively scarce and belonged to the category of high-level talents. However, in recent years, China has always attached great importance to higher education. The expansion of colleges and universities has increased the number of graduates year by year, which has led to the popularity of bachelor's degrees. During the two sessions (the National People's Congress and the Chinese Political Consultative Conference) in 2019, some experts pointed out that the current employment status faces three structural contradictions, namely the contradiction between supply and demand, industry mismatch and regional imbalance. The government work report emphasizes that in the current and even for the coming years, the overall pressure on employment in China will not diminish, and structural problems will still be obvious and other influencing factors will continue to exist. We must give priority to the employment difficulties, and for the first time promote the "employment first" strategy to the state macro-control level. It can be seen that employment is not only the work of people's livelihood, but also an important support for promoting national quality and innovative development [2]. At present, employment of college students has become the focus of Chinese government, society and universities, and difficult employment for college students continuously highlights the problem of general weaker employment ability [3]. In recent years, China's enterprises have continued to develop, and the demand for university graduates has also increased. However, the positions that enterprises can provide cannot meet the full employment needs of college students. With the continuous progress of The Times, the kinds of personnel needed by enterprises are also changing to high-level talents while most of the graduates cannot meet the demands of enterprises for high-level talents due to the lack of their own capabilities. With the rapid development of science and technology, intelligent products have replaced some artificial positions, which increased the pressure on university students' employment. It can be seen that the employment issues of college students in China have become particularly prominent. And today, our country, the whole society, enterprises and universities have made timely responses to the employment difficulties for college students. The state encourages college students to start their own businesses; the government carries out the introduction of talents; numerous state-owned enterprises began to increase the recruitment of fresh graduates and colleges and universities starts to increase the size and number of recruitment fairs. All this established and perfected a talent training system, and provided a favorable guarantee for university students' employment.

\section{College Students Are Confronted with Employment Difficulties}

\subsection{College Students Have Unclear Self-Positioning and Ambiguous Career Goals}

Maslow's hierarchy of needs divides human needs into physiological needs, 
safety needs, social needs, esteem needs, and self-actualization needs. In recent years, China's social stability and rapid economic development have generally improved people's living standards. Most college students are the only child in the family, and their material needs can be satisfied to a large extent. They pay more attention to the needs of self-actualization in employment. Students are too eager to realize their personal values and have high requirements for work, but they lack clear self-awareness and self-positioning, which leads to a large gap between the ideal career and the actual position. Some graduates only focused on studying academic knowledge during their student days, and they lacked internship experiences and social experiences. They also had a poor understanding of the social and corporate environment, and had high expectations of employment environment and corporate payment after graduation. However, this kind of college students' own ability level is not enough to meet the requirements of those positions, leading to failure in application. In general, according to Minnesota's work adaptation theory, when graduates' internal and external satisfactions do not match, graduates cannot find suitable jobs and they thus are unemployed. This forms a vicious cycle of job searching-high-demand-unemployment. There are large differences between cities in China at present, and most graduates flock to developed cities such as Beijing, Shanghai, and Guangzhou after graduation. Those cities have very limited resources, working positions, limited capacity of population bearings, and fierce competition [4]. Most of the talents are gathered in developed cities, and employment is difficult under fierce competition. College students are too obsessed with the pursuit of developed cities. Many times it is not because of lacking job opportunities in big cities, but many college students think that only with high vocational positions, high salaries and working in big cities can they realize the value of life. Under this mode of thinking, the employment scales and employment choices will become narrower which makes it more difficult for college students to be employed.

\subsection{College Students Have Less Access to Information}

Student employment is a hot and difficult problem of society [5]. At present, due to the influence of traditional habits, college students' employment relies too much on job fairs jointly conducted by the universities and various units and their family relations to introduce jobs. They lack their own initiatives and they are not willing to seek jobs themselves [6]. In the era of Internet technology, information and big data, most college students still only use Internet technology at the level of playing games, with poor application of Internet technology and insufficient grasp of data. The focus is only on the traditional ways of looking for jobs. The traditional method of submitting a resume not only consumes a lot of time and energy but also is limited by personal vision and space. Therefore, many people's employment ideas are confined to one single city. As a result, the employment of college students has become a problem. 


\subsection{Graduates Increase Year by Year and Positions in Physical Enterprises Gradually Decrease}

According to relevant statistics: there were 7.95 million college graduates in 2017, 8.2 million in 2018, and 8.34 million in 2019 [7]. As graduates increase year by year, it becomes clear that more and more people will compete for the same position. In China's current society, there are serious shortages of jobs, and this trend is gradually expanding. Judging from the current employment situation in the market, these competitors include previous graduates, fresh graduates, other types of graduates, the unemployed, job-hopping workers and foreigners who have come to work in China. These individuals form a huge group and college students are constantly engaged in fierce competition among them. However there is a stable rule in this competition which is survival of the fittest. This makes the supply-demand relationship of positions more unbalanced, and directly leads to employment difficulties for college students.

With the continuous development of the times and the progress of science and technology, artificial intelligence is gradually integrated into people's lives, bringing a lot of convenience to them. Through program design, the error rate of many precision instruments is reduced to the minimum, and the harm of many jobs to human body shall thus be avoided. But intelligence is like two sides of the same coin. While enjoying the convenience of intelligence, people have brought too many challenges and problems to society. In terms of the employment of college students, the intelligent era has spawned intelligent machines and intelligent equipment. The products of these eras are characterized by high precision, low production costs, and continuous working performances. As a result, more and more production and processing enterprises are willing to use machines to replace workers to increase productivity and reduce production costs. Now many enterprises use machines to replace manual labor for production and processing, which has caused sharp reduction of many positions in physical enterprises. Some highly precise instrument processing tasks are completely conducted by intelligent machines, resulting in the disappearance of physical jobs.

Take finance as an example. In the past, Chinese enterprises used manual bookkeeping, and positions such as financial supervisor or accounting teller required a high degree of professional knowledge. At the same time, a large number of personnel were needed for the financial department of enterprises with more business transactions. In recent years, the emergence of ufida, kingdee and other financial software has greatly reduced the workload of the business, resulting in the streamlining of financial departments. We cannot deny the benefits artificial intelligence has brought to us, but the number of jobs it can provide to the society has been greatly reduced [8]. With the development of science and technology, intelligence will continue to become stronger, and thus the employment situation will be more severe, the number of positions for college students to choose will also be reduced. The era of intelligence somehow becomes a 
problem that college students must face in finding jobs.

\subsection{Enterprises Are Less Willing to Recruit Fresh Graduates}

The development of enterprises is inseparable from talents. Most enterprises will carry out regular recruitment to provide fresh blood for the enterprises, but most companies do not tend to recruit large numbers of fresh graduates. Due to the lack of social experience, work experience, and social understanding and enterprise awareness, when entering an enterprise, the enterprise needs to invest corresponding human and material resources to cultivate those people, which is undoubtedly an additional expense for the enterprise. At the same time, in the process of talent training, with the enhancement of college students' capabilities, some college students gradually become dissatisfied with the status quo and start to leave their working positions and join other companies. This will cause the loss of talents in the enterprise and other certain economic losses to the enterprise. According to the cost theory, enterprises should pay attention to the management of cost in the process of production and operation, pay attention to cost saving, and strive to obtain the maximum profit with less consumption. Under the combined effect of a variety of disadvantages, enterprises might recruit less fresh graduates, resulting in the employment difficulties of graduates.

\subsection{The Polarization of Industries Leads to the Surplus of Talents}

According to the theory of market supply and demand, when the market demand increases, the supply will often increase greatly. If the supply and demand structure cannot be adjusted and controlled in time, the supply and demand structure will become unbalanced, resulting in oversupply. There are popular and unpopular industries in different stages of times. The advancement of science and technology in the 21st century has changed the employment structure, that is to say, the demand for low-income manual labor has decreased while the demand for high-income technology has increased. And there has been a serious two-level differentiation between the popular jobs and unpopular jobs [9]. Popular industries such as computer industry, financial industry, and civil servicing are favored by more people. Unpopular industries such as the construction industry and manufacturing industry are relatively less favored. Most of the majors set up by universities are mainly employment-oriented and aim at popular industries. As a result, most students choose relevant majors to study, and the number of related occupations increases accordingly. At the same time, college students are too obsessed with finding professional counterparts, and most of them have fall into rare positions, which has caused excessive competition for employment. For example, most schools in China set up accounting and computer related majors, and professional graduates have increased year by year. Many of these college students do not have a deep understanding of their majors and lack core competencies, resulting in employment difficulties. 


\section{Countermeasure Analysis of College Students' Employment Issues}

\subsection{School-Enterprise Cooperation to Build a Collaborative Education and Training Platform}

School-enterprise cooperation refers to a collaborative education and training mode established between enterprises and universities. Universities export talents to enterprises, while enterprises cultivate talents for universities, so as to improve the employment and job-seeking skills of college students. Colleges and universities must fully investigate and study the necessary requirements for the social and corporate talents in severely-needed positions, balancing the supply and demand of talents in accordance with the recruitment requirements of enterprises. They should also combine the comprehensive qualities and interests of college students to form a diverse and targeted precise training program, conduct "collaborative education" teaching method under school-enterprise cooperation, increase the opportunities for students to practice and reduce the cost of student internship training. During the student's stay, colleges and universities shall regularly lead students to the cooperation among enterprises, helping them better understand the business model of the enterprise in advance, increasing the opportunities for direct communication between college students and the enterprise, and bringing a preliminary understanding of the specific work content and environment of their own professional future. This will also provide a place for field practices, improve practical ability, and provide a channel for graduates' employment. To be specific, some colleges and universities implement " $3+1$ school-enterprise cooperation project", "school-enterprise training transplant" and "equipment sharing mode", etc. The latter means that colleges and universities invest a part of funds for enterprises to buy equipment, which can provide students with a practical environment. Through school-enterprise cooperation, the employment channels for fresh graduates will be widely broadened.

\subsection{Self-Employment Increases the Employment Rate of Fresh Graduates}

After Prime Minister Li Keqiang proposed "Public Entrepreneurship, Mass Innovation", in recent years, derived from the perspective of social development and economic construction, the country has also issued a number of policies accordingly. For instance, encouraging "double innovation" is conducive to enriching the industrial structure, promoting national consumption, and reducing employment pressure. The diversified innovation main body structure provides soil for innovation and entrepreneurship, and drives the graduates to self-employment jobs instead. China's innovation and international innovation have entered an integrated development pattern, and the ability to integrate resources has been strengthened. Along with the rapid development of sharing economy, industries such as shared bikes and shared charging banks have led to the rapid development of manufacturing and machinery industries, increasing 
the talent gaps of enterprises and providing help to solve the employment issues of college students. From a macro perspective, it is appropriate to lower the employment threshold and expand the employment field. According to Maslow's demand theory, the most basic requirement is physiological demand, and providing social security for college students in innovation and entrepreneurship is conducive to ease the employment difficulties of college students. At present, universities and colleges across the country are conducting research on university student innovation and entrepreneurship projects. At present, universities and colleges across the country are conducting research on university student innovation and entrepreneurship projects. The Ministry of Education, the government, and other departments have organized university student innovation and entrepreneurship competitions at various levels. This has provided sufficient guarantees to enhance university students' interest in innovation and entrepreneurship and stimulates their potential for innovation and entrepreneurship. More college students will be attracted to innovation and entrepreneurship programs and this would lay a solid foundation for their future employment.

\subsection{Establishing and Improving the Career Planning and Employment Guidance Service System for College Students}

In the new era, in order to solve employment difficulties for college students, colleges and universities in our country have promoted and encouraged college students' career planning courses and employment guidance courses under the promotion and encouragement of national policies. Setting up career planning courses after the student has just entered the university is conducive to cultivating college students' good and suitable employment views, and has played an important role in fostering great core values for college students. The career planning course for college students pays attention to students subjective feelings during the process of employment and entrepreneurship trainings, and actively guides college students to establish a more comprehensive and deeper understanding of themselves, so as to enlighten students' employment knowledge. Through MBTI assessment, self-directed Search, Minnesota work adaptation theory, SWOT analysis, CASVE cycle and other assessment methods, students learn about their interests, personalities, abilities and values, and explore the outside world to better shape their own career planning [10]. During the junior year in school, colleges and universities set up employment guidance courses to enhance their job-hunting skills and employment, expand the channels for students to collect information, and play a positive role in promoting the employment of college students. While setting up certain courses, colleges and universities have also set up guidance and consultation rooms for the employment of college students, where professional instructors are sent for providing one-to-one solutions for job-seeking students. During the postgraduate entrance examination and civil service period, colleges and universities will also organize corresponding lectures to offer help for college students. Through the establishment of courses and the construction of consultation platform, college students' 
employment opportunities can be greatly improved.

\subsection{Inviting Companies to Recruit in Schools and Broaden the Job Market}

Employment in colleges and universities is a "first-class project", which affects the future development of college graduates. Colleges and universities attach great importance to this work. Each year, large-scale job fairs in spring and autumn are held to provide employment opportunities for graduates by attracting enterprises to campus. At the same time, colleges and universities will also hold a number of small job fairs for students of different majors each year. Through corporate recruitment on campus, college students and recruiters can communicate effectively face-to-face, and learn more about the job content, salary and other information of the job that they want to apply for, and this surely offers students with more choices. In addition, this also allows younger college students to have a better understanding of the current employment situation, directs college students to a clearer future development, forms a virtuous circle, and improves the employment rate of colleges and universities. In recent years, universities across the country have made full use of alumni resources. Through the liaison between alumni and enterprises, the recruitment companies have been expanded so as to provide opportunities for college students. At the same time, colleges and universities will send personnel to visit relevant enterprises in various places to invite companies to recruit in schools. In order to broaden the college student employment market, colleges and universities in various regions have also launched a number of joint job fairs in recent years, and all those have achieved good results.

\subsection{National Policies Help College Students Find Jobs}

To promote the university students' employment, China has issued a number of policies. In recent years, the policies of Three Supports and One Assistance, Selected Graduates Program, Special Teachers, military service, talent introductions are favored by a great number of college students. The state encourages fresh graduates to work in grass-roots, hard or remote areas, gives them full support in terms of payment and future development, and encourages them to help the country's construction and economic development. At the same time, universities have also responded actively to national calls and promoted national policies at schools, encouraging students to take corresponding exams and participate in those programs. College students with financial difficulties are often faced with more employment difficulties in job hunting due to multiple factors, in which, employment competitiveness becomes the key factor to determine whether they can obtain employment smoothly [11]. At present, colleges and universities across the country have gradually issued job-hunting subsidies for graduates to alleviate the economic problems in their job-hunting. In 2015, Premier Minister Li Keqiang proposed "Public Entrepreneurship, Mass Innovation" to elevate the issue of college students' innovation and entrepreneurship to 
a national strategic level. In recent years, the country has also introduced various policies to encourage college students to start businesses, and has given greater support in terms of funds, places, and technology. College students' self-employment has also become the current trend. Now the number of post graduate admissions in China's universities has increased year by year, which has also eased the pressure on college students' employment, offering more platforms for college students to further their education, and cultivating high-quality talents for the country.

\subsection{Using Internet Technology to Expand Employment Information Channels}

With the rapid development of the Internet industry, recruitment of companies in all the regions of the country can be found on the Internet. However, due to the effectiveness and comprehensiveness of internet information, it is difficult for college students to obtain accurate, current and massive employment information. Based on this situation, each university has established its own official website and WeChat public platform, which collects employment information and forwards it to the official website and platform to expand the channels for college students to obtaining employment information. This has greatly increased the possibility of college students' employment and provided guarantees for the better development of college students. University official websites and WeChat official platforms can also offer college students and graduates with the newest and broadest employment information and other national policies. Students can easily get access to and obtain relevant employment information in the first time, and grasp timely of corporate trends and lay a solid foundation for their future career development. Similarly, the WeChat public platform will also update the video teaching of resume production and job etiquette from time to time, which is convenient for college students to learn the information needed in job-hunting.

\section{Conclusion}

With the expansion of college enrollment, the number of college graduates will increase year by year, and the employment situation is not optimistic. However, various measures and policies issued by the state, society, enterprises, and universities are targeted to graduates to ensure the stability of graduates' employment and the improvement of employment environment. At the same time, universities have also developed professional disciplines and improved personnel training systems for emerging industries in line with the development of the times, which is conducive to improve the employability of college students. College students should also keep pace with the times, broaden their horizons, learn more knowledge, and adapt themselves with the future employment environment. Through the unremitting efforts of the state, society, enterprises, universities and college students themselves, the comprehensive quality and job-hunting ability of contemporary college students will be greatly improved. High-quality 
talents should be provided for national construction and social development.

\section{Conflicts of Interest}

The authors declare no conflicts of interest regarding the publication of this paper.

\section{References}

[1] Fan, Z.Y. (2008) Study on the Actuality and the Countermeasures of the Employment of College Students. International Education Studies, 1, 145-149.

[2] Du, B.H. (2019) To Deduce the Employment Policy Trend from This Year's Government Work Report. China University Students Career Guide, No. 7, 5-8. (In Chinese)

[3] Xu, H.H., Wang, Y.H. and Li, Z. (2010) Empirical Study on the Elements of Employment Ability of College Students Based on Employing Unit. International Conference on E-Business \& E-Government, Guangzhou, 7-9 May 2010.

[4] Shen, D.H. (2014) Discussion on the Changes of College Students' Employment Value Orientation and Countermeasures. Heilongiiang Researches on Higher Education, No. 2, 123-125. (In Chinese)

[5] Peng, Y. and Wei, Y.X. (2012) Employment of College Students Research Based on Long Tail Theory. Engineering Education and Management, 1, 523-529. (In Chinese) https://doi.org/10.1007/978-3-642-24823-8_83

[6] Liu, Z.Y. (2019) Comprehensive Analysis of College Students' Employment Issues. New West, No. 15, 114-115. (In Chinese)

[7] Liu, Y. and Yu, E.D. (2019) Analysis of College Students' Employment Pressure under the New Employment Situation. CO-Operative Economy \& Science, No. 17, 119-121. (In Chinese)

[8] Ma, Y.Q. (2013) Talents Training Model, Labor Market and College Graduates' Employment. Journal of Higher Education, 34, 34-39. (In Chinese)

[9] Lou, S.Z. and Lin, H.B. (2013) College Students' Structural Employment Imbalance: An Empirical Analysis by Profession and Industry. Tsinghua Journal of Education, 34, 109-117. (In Chinese)

[10] He, Y.N., Zhu, X.L. and Liu, F. (2018) Exploration on Ideological and Political Reform of College Students' Career Planning Courses. Course Education Research, No. 16, 47-48. (In Chinese)

[11] Jiang, J.Y., Yao, J.F. and Wan, J.Y. (2016) Research on Cultivation Mode of Employment Competitiveness of College Students with Financial Difficulties. Academics in China, No. 6. 